\title{
Formulation and evaluation of sustained release mucoadhesive microspheres of lornoxicam by using novel isolated polymer of fruit artocarpus heterophyllus
}

\author{
Bebee Pathare $^{1}$, Vrushali Tambe ${ }^{2, *}$, Dnyaneshwari Waichal ${ }^{3}$, Rahul Chanshetti $^{4}$, Rohini Pujari $^{5}$ \\ ${ }^{1,3}$ Research Scholar, ${ }^{2}$ Associate Professor, ${ }^{4,5}$ Asssitant Professor, Department of Quality Assurance, P. E. S's, Modern College of
} Pharmacy (for ladies), Dist. Pune, Maharashtra, India

*Corresponding Author:

Email: vrushalitambe99@gmail.com

\begin{abstract}
Objective: To investigate the potential of novel polymer isolated from fruit Artocarpus heterophyllus for mucoadhesion and sustained release action. Microspheres containing Lornoxicam formulated using isolated polymer offered a suitable, practical approach to achieve a prolonged therapeutic anti-inflammatory effect by continuously releasing the medication over extended period of time.

Materials and Methods: D-Optimal design was applied to optimize the fruit polymer and sodium tripolyphosphate concentration which was used as a cross-linking agent.

Result: Fruit polymer and sodium tripolyphosphate concentration has significant impact on \% entrapment efficiency, mucoadhesivity, and in vitro release. Differential scanning calorimetry and infrared spectroscopy results indicates that no interaction between drug and excipients. Polynomial models were validated using one way ANOVA and results indicated that isolated fruit polymer and sodium tripolyphosphate used have significant effect on selected response $(\mathrm{p}<0.05)$. Contour plots and three dimensional response surface curves were drawn. In vivo studies were carried out for the optimized formulation. Furthermore, the pharmacokinetic parameters of the Lornoxicam microspheres showed constant release with minimum fluctuation in plasma drug concentration. The in vivo pharmacokinetic studies clearly demonstrate that microspheres of Lornoxicam shows sustained release action for $24 \mathrm{hrs}$.

Conclusion: From the result of the present work, it was concluded that preparation of Lornoxicam loaded microspheres by ionic gelation technique using novel isolated polymer from fruit of Artocarpus heterophyllus might be promising approach for sustained release mucoadhesive formulations.
\end{abstract}

Keywords: Artocarpus heterophyllus, Ionic gelation, In-vivo, Mucoadhesion.

\section{Introduction}

Microsphere is defined as a spherical particle with size varying from $1-1000 \mu \mathrm{m}$, containing a core substance. ${ }^{1}$ Microspheres are normally free flowing powders. ${ }^{2}$

The success of novel sustained formulation is limited due to their short residence time at the site of absorption. Therefore, it would be beneficial to have means for providing an intimate contact of the drug with the absorbing mucous membranes. It can be achieved by coupling mucoadhesion characteristics to microspheres. Mucoadhesive microspheres show an extended residence time at the site of absorption and make possible an intimate contact with underlying absorption mucous membrane and thus contribute to better therapeutic performance of drug. ${ }^{3}$

Lornoxicam is a non-steroidal anti-inflammatory drug that belongs to the oxicam class and is used for the management of pain. Lornoxicam acts by decreasing prostaglandin synthesis by inhibiting cyclo-oxygenase, exhibiting antipyretic, analgesic, and anti-inflammatory effects. ${ }^{4}$ It can be effectively used for symptomatic relief of inflammation of the joints in rheumatic disease $^{5-7}$ Lornoxicam shows very less solubility in acidic conditions. ${ }^{8}$ Lornoxicam has good intestinal tolerability as compared with other oxicams. ${ }^{9}$ Lornoxicam is well absorbed in the lower GIT, but has a very short biological half-life of 3-5 hrs. ${ }^{10}$ This formulation is tailored to achieve sustained drug release in the intestine using a novel excipients obtained from fibrous part of fruit Artocarpus heterophyllus. This also reduces dosing frequency, gastric irritation associated with anti-inflammatory agents.

\section{Materials and Methods Materials}

Lornoxicam was obtained as gift sample from Kores India Limited, Navi Mumbai. Chitosan, Sodium tripolyphosphate were purchased from Loba chemie Pvt Ltd, Mumbai.

Collection of fruit: Jackfruit was collected from local market and authenticated by Botanical survey of India.

Isolation of polymer from jackfruit: To remove dirt and debris fruit was thoroughly washed with water. Incisions were made on fruit, left over night and then cut into pieces. The seeds present inside the fruit were removed. The fibre part of the fruit was crushed and soaked in water for 4-5 hours, boiled for $30 \mathrm{~min}$, and left to place for 1 hour to allow total release of polymer into the water. The polymer was extracted using muslin cloth to remove the marc from the solution. Ethanol (three times volume of filtrate) was used to precipitate the polymer. The polymer was separated, dried at $45^{\circ} \mathrm{C}$, 
grounded and passed through a \#80 sieve and keep in desicator till use. ${ }^{11-13}$

\section{Preparation of Lornoxicam loaded microspheres using $3^{2} \mathrm{D}$ optimal design}

Lornoxicam loaded microspheres were prepared by using ionic gelation method. Chitosan was dissolved in
$1 \% \mathrm{v} / \mathrm{v}$ acetic acid solution. Lornoxicam was dispersed in chitosan solution (2\%). Then fruit polymer solution was added in the above mixture. This mixture was then dispersed in sodium tripolyphosphate (TPP) solution by using syringe and stirred for 1 hour. Microspheres were filtered and washed with water. (Table 1)

Table 1: Formulation of microspheres by using $3^{2}$ D-optimal design

\begin{tabular}{|l|c|c|c|c|c|}
\hline Batch No. & $\begin{array}{c}\text { Drug } \\
(\mathbf{\%})\end{array}$ & $\begin{array}{c}\text { Chitosan } \\
(\mathbf{\%})\end{array}$ & $\begin{array}{c}\text { Fruit polymer } \\
(\mathbf{\%})\end{array}$ & $\begin{array}{c}\text { TPP } \\
(\mathbf{\%})\end{array}$ & $\begin{array}{c}\text { Cross linking } \\
\text { time (hours) }\end{array}$ \\
\hline F1 & 2 & 2 & 0.5 & 0.5 & 1 \\
\hline F2 & 2 & 2 & 0.5 & 0.75 & 1 \\
\hline F3 & 2 & 2 & 0.5 & 1 & 1 \\
\hline F4 & 2 & 2 & 1 & 0.5 & 1 \\
\hline F5 & 2 & 2 & 1 & 0.75 & 1 \\
\hline F6 & 2 & 2 & 1 & 1 & 1 \\
\hline F7 & 2 & 2 & 1.5 & 0.5 & 1 \\
\hline F8 & 2 & 2 & 1.5 & 0.75 & 1 \\
\hline F9 & 2 & 2 & 1.5 & 1 & 1 \\
\hline
\end{tabular}

Surface morphology: The surface morphology of Lornoxicam microspheres was examined using scanning electron microscopy (JEOL JSM- 6360A scanning microscope, Tokyo, Japan) at $10 \mathrm{kV}$.

Particle size: Particle size was measured by using motic microscope. Sample was placed on the stage micrometer slide and particle size was measured.

Percent entrapment efficiency: $10 \mathrm{mg}$ of microspheres were accurately weighed, crushed and transferred to a conical flask containing $100 \mathrm{ml}$ of phosphate buffer ( $\mathrm{pH}$ 6.8). The flask was placed on rotary shaker at $100 \mathrm{rpm}$ for $24 \mathrm{hrs}$. After $24 \mathrm{hrs}, 1 \mathrm{ml}$ sample was withdrawn and volume was made up to 10 $\mathrm{ml}$ by phosphate buffer ( $\mathrm{pH}$ 6.8). Absorbance was taken by using UV spectrophotometer at $376 \mathrm{~nm}$ and concentration of drug was calculated. The \% entrapment efficiency was calculated by formula:

$\%$ Entrapment efficiency $=$ (Practical content/Theoretical content) x 100

\section{Ex vivo Percent Mucoadhesivity}

The mucoadhesive capacities of the Lornoxicam microspheres are evaluated by ex vivo wash off test by using goat mucosa. A piece $\left(1 \mathrm{~cm}^{2}\right)$ of goat mucosa was tied on a glass slide using thread. Lornoxicam microspheres were spread on to the rinsed mucosa and then prepared slide was hung onto one of the grooves of a USP disintegration apparatus. The apparatus is operated such that the mucosa is given regular up and down movements in a beaker containing $900 \mathrm{ml}$ of phosphate buffer $\mathrm{pH}$ 6.8. The adhering number of microspheres to the mucosa was counted at defined interval. ${ }^{14,15}$

$\%$ Mucoadhesion $=$ no. of microspheres remains $/$ no. of applied microspheres x 100

\section{Swelling study}

$50 \mathrm{mg}$ of dried microspheres were accurately weighed and placed in a $50 \mathrm{ml}$ of phosphate buffer $(\mathrm{pH}$ 6.8). Swelling was allowed to occur at room temperature for $24 \mathrm{hrs}$. After $24 \mathrm{hrs}$, microspheres were removed from medium and blotted with filter paper to remove adsorbed solvent on the surface and weighed immediately. Percent degree of swelling was calculated by using formula:

$\%$ Degree of swelling $=($ Weight of swollen microspheres - Initial weight/ Initial weight) x100

\section{Flow properties}

The microspheres were evaluated for bulk density, tapped density, angle of repose, Carr's index and Hausner's ratio to find flow properties of microspheres.

\section{Compatibility study}

IR Spectroscopy: The FT-IR spectrophotometer was used to record FT-IR spectra of Lornoxicam, physical mixture and formulation to check the compatibility between drug and polymer.

Differential Scanning Calorimetry: Lornoxicam and formulation were subjected to DSC studies by using differential scanning calorimeter equipped with computer analyzer (JAPE DSC, Perkin elmer, USA). Samples were heated under nitrogen atmosphere on an aluminium pan at a heating rate of $10^{\circ} \mathrm{C} / \mathrm{min}$ over the temperature range of $50^{\circ} \mathrm{C}-300^{\circ} \mathrm{C}$.

Powder X-ray diffraction studies: Powder X-ray diffraction (PXRD) patterns were traced by using X-ray diffractometer $\mathrm{D}_{8}$ advanced model of Bruker Axs Company fitted with copper target.

In-vitro drug release studies: In-vitro drug release studies were carried out by using USP type II dissolution test apparatus filled with $900 \mathrm{ml}$ of phosphate buffer $\mathrm{pH}$ 6.8. Weighed quantity of 
microspheres (equivalent to $16 \mathrm{mg}$ ) was added to dissolution medium. The dissolution test was performed at $37^{\circ} \mathrm{C}$ at $100 \mathrm{rpm}$. At predetermined intervals, $5 \mathrm{ml}$ of the medium was sampled and filtered and it was immediately replaced by the same volume of fresh dissolution media to maintain sink condition. Then, the concentration of Lornoxicam was analyzed by UV spectroscopy at $376 \mathrm{~nm}$ against blank. All the determinations were made in triplicate.

\section{In vivo study}

In vivo experiment: The protocols for the animal studies were approved by the Institutional Animal Ethical Committee (CPCSEA) New Delhi [Approval no. 1036/a/07/CPCSEA/IAEC/12-13/E-9]. Male Albino Wistar rats weighing 250-300 g were fasted for $12 \mathrm{~h}$ prior to the experiments but allowed free access to water. The rats were administered with the Lornoxicam microspheres. Then blood was collected from the retroorbital route at predetermined time intervals and centrifuged at $12,000 \mathrm{rpm}$ for $10 \mathrm{~min}^{16}$

Preparation of sample solution: To $0.2 \mathrm{ml}$ of plasma, $0.6 \mathrm{ml}$ methanol and $0.4 \mathrm{ml}$ of trichloroacetic acid (10\% w/v) were added to a glass tubes. Each sample was vortexed for $3 \mathrm{~min}$ and centrifuged at $8000 \mathrm{rpm}$ for 10 min. After centrifugation, $50 \mu \mathrm{l}$ aliquots of supernatant of each concentration were filtered and then injected into the HPLC system. ${ }^{17}$

Pharmacokinetic data analysis: The area under curve (AUC), half-life $\left(\mathrm{t}_{1 / 2}\right)$, the elimination rate constant $\left(\mathrm{K}_{\mathrm{el}}\right)$ were calculated. The maximum plasma concentration of drug (Cmax) and the time taken to reach the maximum plasma concentration (Tmax) were obtained from data.

\section{Statistical Analysis}

Design and summary response data was obtained by subjecting the independent variables and response parameters to statistical analysis like ANOVA using the software "Design Expert ${ }^{\mathrm{TM}}$ 8.0.7.1 VERSION".

\section{Result and Discussion}

Surface morphology: The surface morphology of the Lornoxicam microspheres is shown in Fig. 1. The SEM micrographs of lornoxicam microspheres appeared as spherical shape with rough surface.

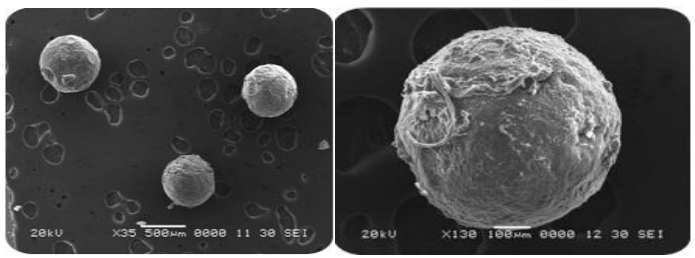

Fig. 1: SEM image of microspheres

Particle Size: Particle size was determined by using Motic Microscope. The particle size was found to be in the range of $350-500 \mu \mathrm{m}$. The particle size increased with the increase of fruit polymer and TPP concentration. This can be explained by the increase of viscosity, which resulted in larger emulsion droplets and finally in greater microsphere size. Furthermore, increasing the polymer concentration, increases the cross-linking, therefore increasing the matrix density of the microspheres. Particle size also increased with the increase of TPP concentration and the cross-linking time. Particle size of different batches is shown in table 2.

Table 2: Data of and Particle size, Entrapment efficiency, mucoadhesivity and swelling index

\begin{tabular}{|l|c|c|c|c|}
\hline Formulation & $\begin{array}{c}\text { Particle } \\
\text { size }(\boldsymbol{\mu m})\end{array}$ & $\begin{array}{c}\text { Entrapment } \\
\text { efficiency } \\
(\boldsymbol{\%})\end{array}$ & $\begin{array}{c}\text { Mucoadhesivity } \\
(\boldsymbol{\%})\end{array}$ & $\begin{array}{c}\text { Swelling } \\
\text { Index } \\
(\boldsymbol{\%})\end{array}$ \\
\hline F1 & $350-365$ & $86.18 \pm 1.41$ & $68 \pm 2.64$ & 32.66 \\
\hline F2 & $350-370$ & $85.11 \pm 0.83$ & $66 \pm 1.00$ & 31.74 \\
\hline F3 & $350-380$ & $83.00 \pm 2.01$ & $64 \pm 2.12$ & 30.05 \\
\hline F4 & $410-420$ & $91.66 \pm 1.73$ & $79 \pm 1.00$ & 49.14 \\
\hline F5 & $410-425$ & $90.53 \pm 0.92$ & $77 \pm 2.64$ & 48.50 \\
\hline F6 & $410-430$ & $88.66 \pm 1.52$ & $75 \pm 1.73$ & 47.23 \\
\hline F7 & $480-490$ & $95.00 \pm 2.01$ & $86 \pm 1.00$ & 55.96 \\
\hline F8 & $480-495$ & $92.66 \pm 1.00$ & $84 \pm 1.58$ & 54.79 \\
\hline F9 & $480-495$ & $91.33 \pm 1.72$ & $83 \pm 1.58$ & 52.32 \\
\hline
\end{tabular}

Percent entrapment efficiency: Results suggest that the increase of Fruit polymer concentration from 1 to $1.5 \%$ $(\mathrm{w} / \mathrm{v})$ led to a higher \% Entrapment efficiency. A reasonable explanation for this fact is the increase of fruit polymer concentration leads to greater viscosity which prevents drug crystals from leaving the droplets. The effect of TPP concentration on \% entrapment efficiency of Lornoxicam in microspheres was also studied, and results suggest that $\%$ entrapment efficiency decreased with the increase of TPP concentration. This increased concentration causes increase in the $\mathrm{pH}$ of medium. Lornoxicam has high solubility at high $\mathrm{pH}$, thereby allowed the leaching out of Lornoxicam from the microspheres. Variations of \% entrapment efficiency amongst the different formulations of microspheres are depicted in table no.2, and were obtained within the range 83-95\%. 
Ex vivo Percent Mucoadhesivity: Ex vivo mucoadhesion of microspheres was the most important aspect of present investigation. The mucoadhesion study was performed with intestinal mucous membrane of goat. It was found that mucoadhesivity increased with increasing concentration of fruit polymer. This may be due to the fact that, as the amount of fruit polymer increased, the group available for binding with the mucous layer also increases, that result in the increase in the ex vivo mucoadhesion of microspheres.

Swelling index: The swelling capacity of formulations was found in the range between 30-55\% as shown in table 2 . From result it was found that, swelling capacity of microspheres incresess with increasing concentration of fruit polymer and decreased with increasing TPP concentration due to increase in crosslinking.

Flow properties: The values of Carr's index, angle of repose and Hausner's ratio were found to be in the range of $8.06-14.06,16.98-24.22$ and less than 1.2 respectively. (Table 3)

Table 3: Flow properties of microspheres

\begin{tabular}{|c|c|c|c|c|c|}
\hline Batch code & $\begin{array}{c}\text { Bulk } \\
\text { density } \\
(\mathrm{gm} / \mathbf{m l})\end{array}$ & $\begin{array}{l}\text { Tapped } \\
\text { density } \\
(\mathrm{gm} / \mathrm{ml})\end{array}$ & $\begin{array}{c}\text { Carr's } \\
\text { index } \\
(\%)\end{array}$ & $\begin{array}{c}\text { Hausner's } \\
\text { ratio }\end{array}$ & $\begin{array}{c}\text { Angle of } \\
\text { repose } \\
{\left[\text { Degree }\left({ }^{0}\right)\right]}\end{array}$ \\
\hline F1 & 0.55 & 0.62 & 11.29 & 0.88 & 18.26 \\
\hline F2 & 0.57 & 0.65 & 12.30 & 0.87 & 17.74 \\
\hline F3 & 0.52 & 0.60 & 13.33 & 0.86 & 22.34 \\
\hline F4 & 0.56 & 0.64 & 12.50 & 0.87 & 21.54 \\
\hline F5 & 0.54 & 0.61 & 11.47 & 0.88 & 24.22 \\
\hline F6 & 0.55 & 0.61 & 9.83 & 0.90 & 21.80 \\
\hline F7 & 0.57 & 0.62 & 8.06 & 0.91 & 20.80 \\
\hline F8 & 0.52 & 0.59 & 11.86 & 0.88 & 17.45 \\
\hline F9 & 0.55 & 0.64 & 14.06 & 0.85 & 16.98 \\
\hline
\end{tabular}

\section{Compatibility study}

Infra-Red Spectroscopy: The FT-IR spectra of physical mixtures were compared with the FT-IR spectrum of Lornoxicam (Fig. 2a). The drug Lornoxicam exhibited its characteristic absorption bands at $3071.08 \mathrm{~cm}^{-1}$ due to aromatic/heterocyclic $\mathrm{C}-\mathrm{H}$ stretching. The other prominent absorption bands appeared at $1738 \mathrm{~cm}^{-1}$ due to of $\mathrm{C}=\mathrm{O}$ of stretching. The peaks at $1328 \mathrm{~m}^{-1}$ correspond to $\mathrm{C}-\mathrm{N}$ stretch aromatic amine, $795.49 \mathrm{~cm}^{-1}$ due to $\mathrm{C}-\mathrm{Cl}$ stretching vibrations. The IR spectra of physical mixture show all the characteristic absorption bands as that of pure drug Lornoxicam without any significant variations (Fig. 2b). It is clear from the spectra that, the drug has not undergone any kind of chemical interactions with the excipients used and retained its identity in its physical mixture.

The IR spectra of the formulation exhibited all the characteristic peaks of Lornoxicam. Therefore, it was concluded that Lornoxicam is stable in formulation (Fig. 2c).

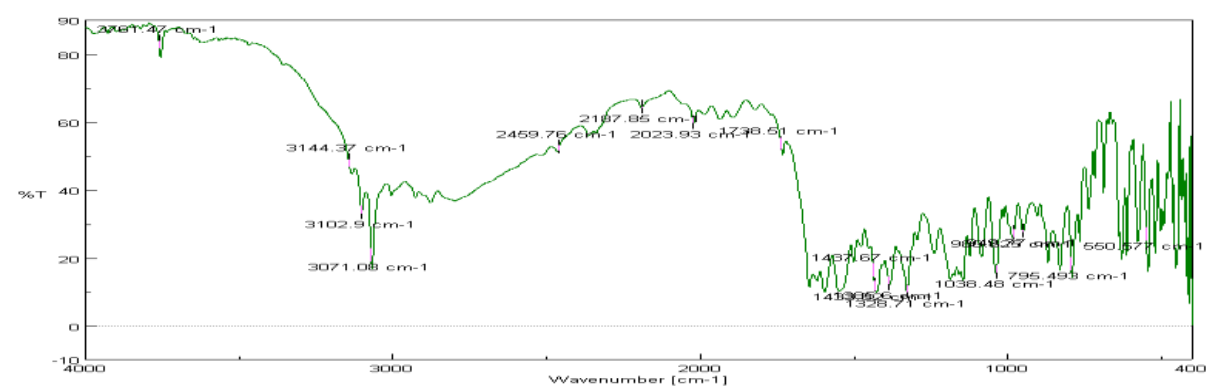

Fig. 2a: FTIR spectra of Lornoxicam

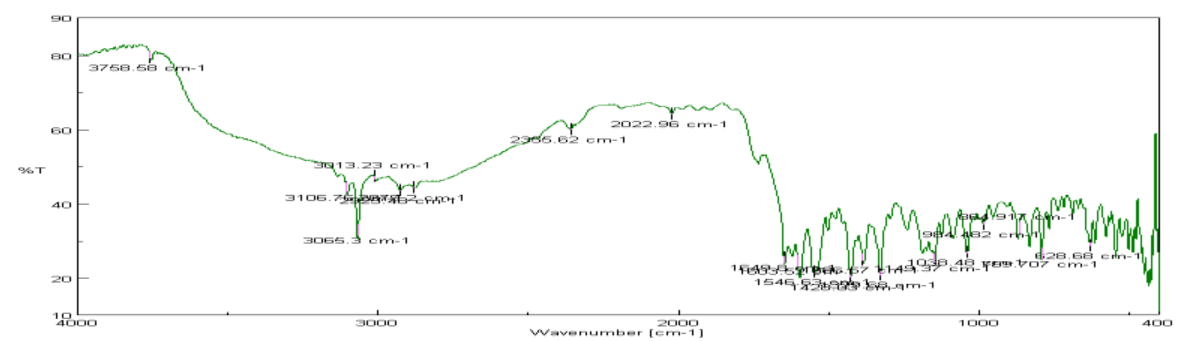

Fig. 2b: FTIR Spectra of physical mixture (Lornoxicam, chitosan, fruit polymer) 


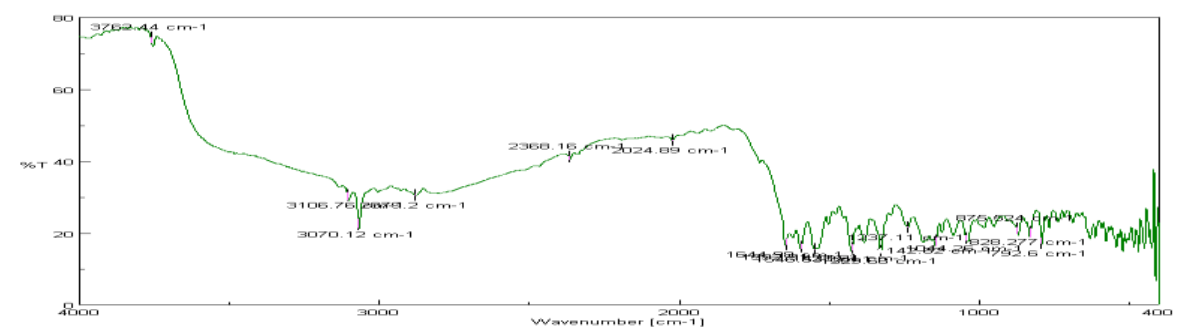

Fig. 2c: FTIR Spectra of formulation F7

DSC Spectroscopy: Differential scanning calorimetric analysis was also performed in order to establish the identity and integrity of drug in its pure form, and also in the microsphere formulation (Fig. 3). The Lornoxicam exhibited a single sharp exothermic peak at $219.98{ }^{\circ} \mathrm{C}$, which corresponds to its melting point and indicating its crystalline nature. The DSC thermogram of the formulation showed an existence of the Lornoxicam exothermic peak at 221.03 ${ }^{\circ} \mathrm{C}$ indicating no interaction between the drug and the excipients.

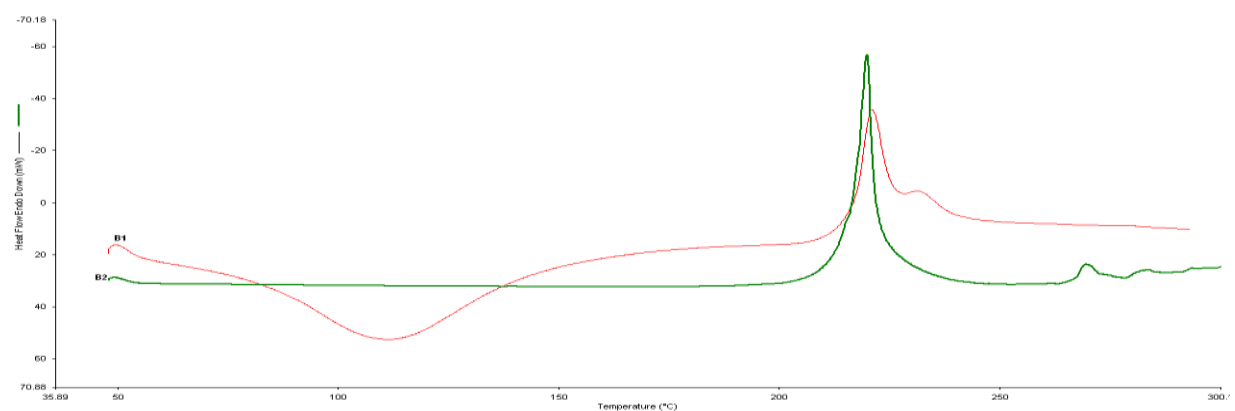

Fig. 3: DSC thermograph of overlay of formulation F7 [A] and Lornoxicam [B]

P-XRD Studies: The crystallinity of Lornoxicam was assessed by XRD as shown in Fig. 4. The XRD pattern of Lornoxicam showed intense peaks which is indicative of its crystalline nature (Fig. 4a A). However, the diffractogram of the Lornoxicam loaded microspheres (Fig. 4a B) showed peaks of diminished intensities indicating that the drug is molecularly dispersed in the polymeric matrix or might have undergone conversion to amorphous form during the microsphere preparation.

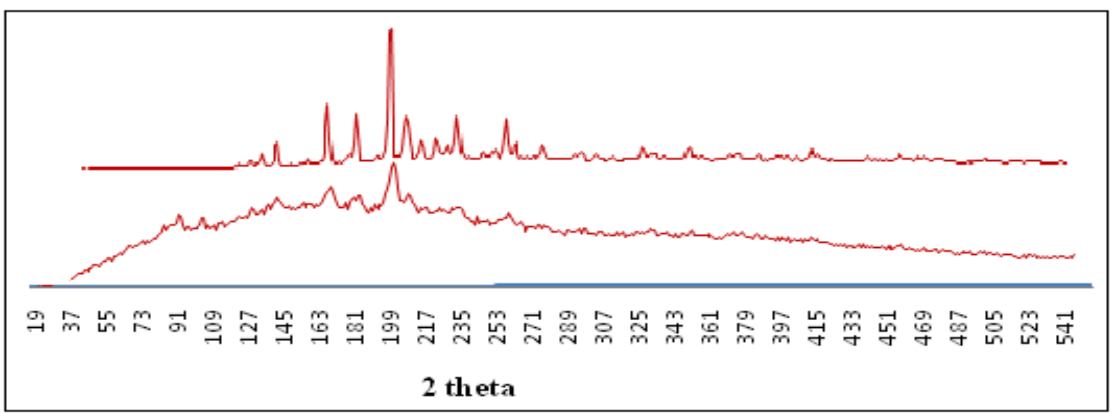

Fig. 4: X-ray diffractogram of Lornoxicam[A], Formulation[B]

In vitro drug release: The in vitro release study of formulations was carried out using USP Type II apparatus. The release profile of Lornoxicam from optimized batch (F7) and marketed formulation (Lofecam SR tablet) at pH 6.8 phosphate buffer is shown in figure 5a. From result, it was concluded that amount of Lornoxicam release from microspheres decreased with increasing concentration of fruit polymer and TPP. It might be due to the high crosslinking density which prevents the swelling of the microspheres and further reducing Lornoxicam quantities released. 


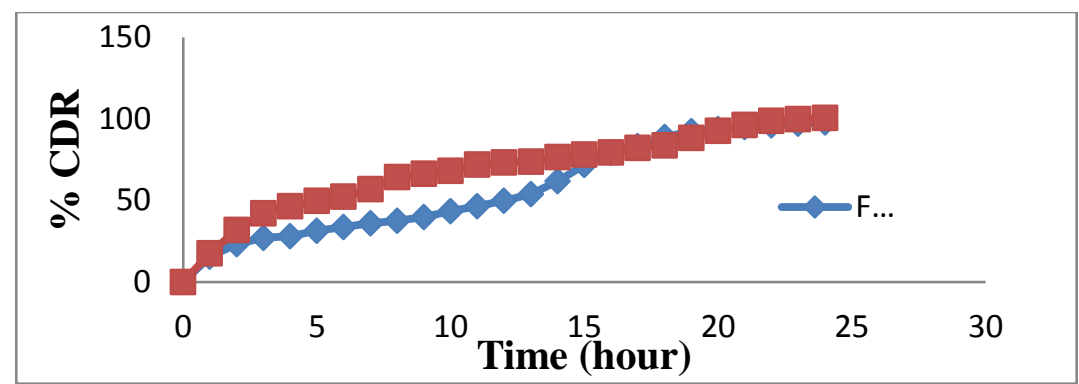

Fig. 5a: \% CDR for optimized batch (F7) and marketed formulation (Tab)

In-vivo study: The sustained release action of Lornoxicam microspheres was evaluated in rats. Fig. $5 \mathrm{~b}$ shows the mean plasma concentration-time profile of Lornoxicam microspheres obtained after oral administration of a single dose of a Lornoxicam. Results indicate that formulation shows sustained release action for $24 \mathrm{hrs}$ with minimum fluctuation in plasma drug concentration. The Cmax value of Lornoxicam microspheres was $1.90 \mu \mathrm{g} / \mathrm{ml}$ at tmax $3 \mathrm{~h}$. After $24 \mathrm{hrs}$, plasma drug concentration decreased gradually. These in vivo pharmacokinetic studies clearly demonstrate that microspheres of Lornoxicam shows sustained release action for $24 \mathrm{~h}$.(Table IV) There was no interference between the endogenous peaks in the rat plasma and the peaks for Lornoxicam (Fig. 5c).

Table 4: Pharmacokinetic parameters of Lornoxicam in rats after oral administration

\begin{tabular}{|l|l|c|}
\hline Sr. no. & $\begin{array}{c}\text { Pharmacokinetic } \\
\text { parameter }\end{array}$ & Result \\
\hline 1 & Cmax $(\mu \mathrm{g} / \mathrm{ml})$ & 1.90 \\
\hline 2 & Tmax $(\mathrm{hr})$ & 3.0 \\
\hline 3 & $\mathrm{AUC}(\mu \mathrm{g} \mathrm{hr} / \mathrm{ml})$ & 14.17 \\
\hline 4 & $\mathrm{Ke} \mathrm{hr}^{-1}$ & 0.128 \\
\hline 5 & $\mathrm{t}_{1 / 2}(\mathrm{hr})$ & 5.41 \\
\hline
\end{tabular}

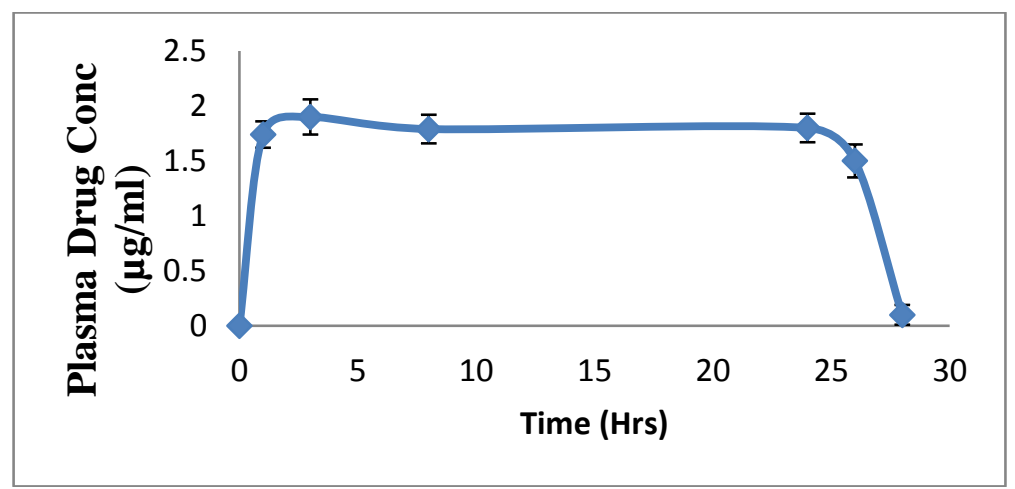

Fig. 5b: Plasma concentration-time profile of Lornoxicam

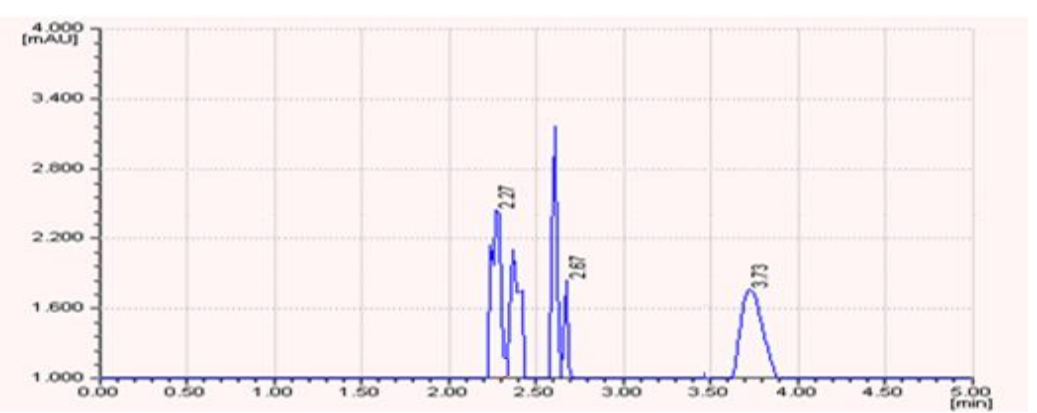

Fig. 5c: Chromatogram of plasma sample

\section{Statistical analysis}

The results were analyzed by one way ANOVA. Optimization of microspheres was carried out by $3^{2} \mathrm{D}$ optimal design by using Design expert 8.0.7.1 software. Values of "Prob > F" less than 0.05 indicate model terms were significant. 
ANOVA for response $1 \%$ CDR: The model for \% CDR was found to be significant $(p<0.05)$. The results of linear multiple regression analysis revealed that on increasing the fruit polymer concentration, percent cumulative drug release decreases. Similarly, on increasing TPP concentration \% CDR decreases. Percent cumulative drug release decreases with combined increase in both fruit polymer concentration and amount of cross linking agent TPP.

Contour plot and Surface plot of the design: The influence of the variables on the \% CDR was further elucidated using the response surface graph. The Contour plot and Three-dimensional (3D) plot (figure 6a) for the measured responses were formed, based on the model polynomial functions to assess the change of the response surface. Also the relationship between the dependent and independent variables can be further understood by these plots.

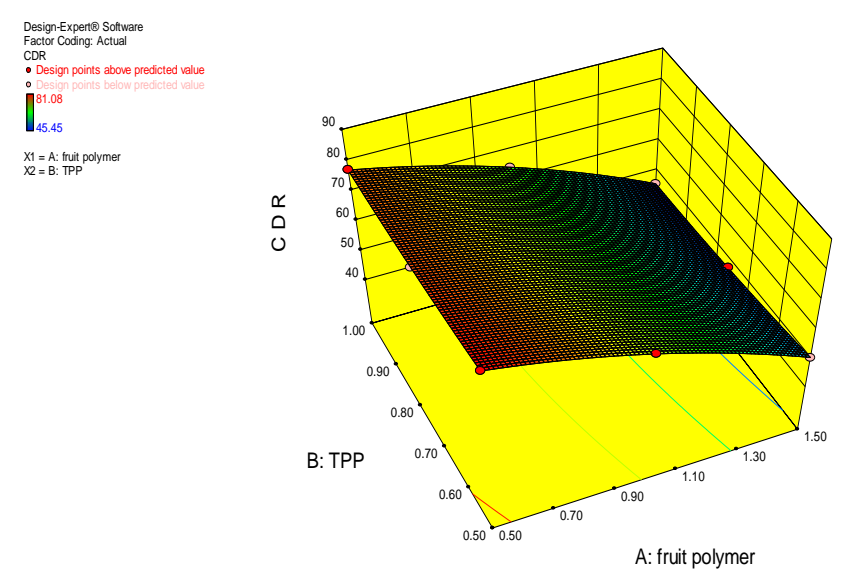

Fig. 6a: 3D Surface plots showing the effect of fruit polymer concentration and amount of TPP on \% Cumulative drug release

ANOVA for response $2 \%$ Entrapment efficiency: The model for \% Entrapment efficiency (Response 2) was found to be significant $(p<0.05)$. The results of linear multiple regression analysis revealed that on increasing the fruit polymer concentration, percent entrapment efficiency increases and entrapment efficiency decreases with increase in amount of TPP. Contour plot and Surface plot of the design for entrapment efficiency are shown in Fig. $6 b$.
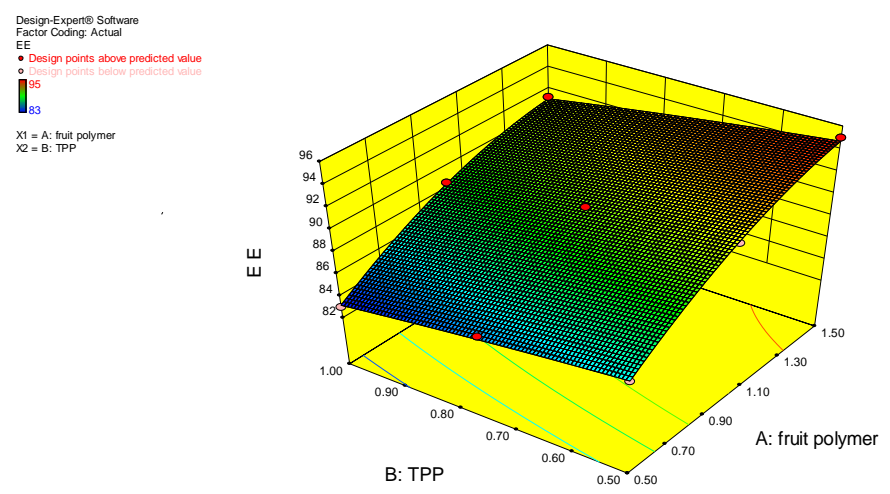

Fig. 6b: 3D Surface plots showing the effect of fruit polymer concentration and amount of TPP on \% entrapment efficiency

ANOVA for Response $3 \%$ Mucoadhesion: The model for \% Mucoadhesion (Response 3) was found to be significant $(p<0.05)$. The results of linear multiple regression analysis revealed that on increasing the fruit polymer concentration, percent mucoadhesion increases. Contour plot and Surface plot of the design for \% mucoadhesion are shown in Fig. 6c. 


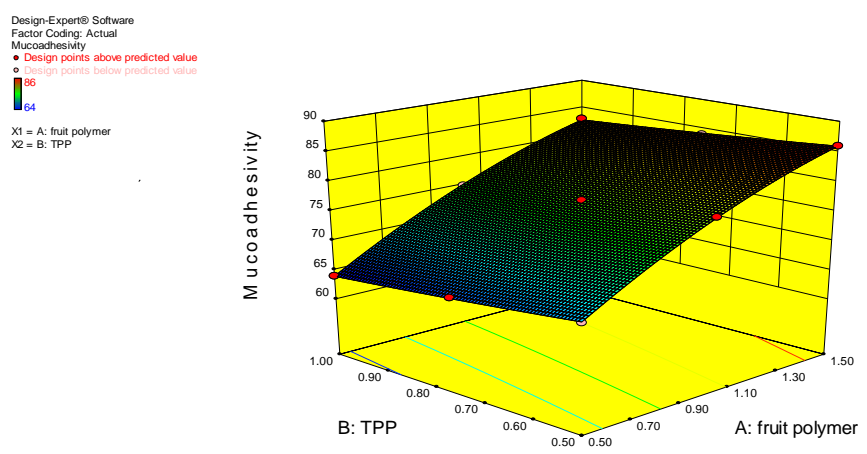

Fig. 6c: 3D Surface plots showing the effect of fruit polymer concentration and amount of TPP on \% Mucoadhesion

\section{Conclusion}

From the results of the present work, it can be concluded that the isolated polymer from fibre part of fruit of Artocarpus heterophyllus has a potential as an excipients in pharmaceutical formulation for sustained release action and mucoadhesivity. D-optimal design was found to be effective in developing an optimized formulation with a minimum number of experiments. The optimal formulation was obtained with fruit polymer concentration of $1.5 \%(\mathrm{w} / \mathrm{v})$ and TPP $1 \%$ $(\mathrm{w} / \mathrm{v})$. The encapsulation efficiency of $95.00 \pm 2.01 \%$ and mucoadhesivity $86 \pm 1.00$ was achieved. In vivo studies carried out on male wistar albino rats, revealed a significant sustained and constant release of Lornoxicam for $24 \mathrm{hrs}$. From the overall study (in vitro and in vivo) it was found that isolated fruit polymer was able to prolong the drug release for $24 \mathrm{hrs}$. Thus it was concluded that isolated fruit polymer can be successfully used for sustained release action for once a daily dosage form. Hence this formulation will be a boon to novel drug dosage forms due to tailored drug release characteristics in the intestine and lower GIT. This work throws some light on and helps further research on isolated polymer from fibre part of fruit Artocarpus heterophyllus.

\section{Acknowledgements}

Authors are grateful to Kores India Limited, Navi Mumbai for providing gift samples of Lornoxicam.

\section{References}

1. Vyas S. P., Khar R. K., 2002.Targeted and Controlled Drug Delivery: Novel Carrier System $1^{\text {st }}$ edition. CBS publication and distributors, New Delhi,417-43.

2. Rathore B., A. Yadav, G. Nayak, G. K. Saraogi, SinghaiA. K., 2012. A review on microspheres as drug delivery carriers for management of diabetes mellitus, international journal of pharmacy \& life sciences. 3,206470 .

3. Kora P., Chowdary R., and Rao Y. S., 2004. Mucoadhesive Microspheres for Controlled Drug Delivery, Biol. Pharm. Bull. 27,1717-24.

4. Liu Y., Zhang W., Tan ZR., Ouyang DS, Luo C., Liu ZQ., Qiu Y., Chen Y., He YJ., Zhou G., Zhou HH., 2006.
Effect of the CYP2C9*3 allele on lornoxicam metabolism, Clinica Chimica Acta. 364,287-91.

5. Chemate S. Z., Chowdary K.P.R, 2012. A factorial study on enhancement of solubility and dissolution rate of lornoxicam employing hp- $\beta$-cyclodextrin and surfactants, International journal of pharmaceutical sciences and research. 3,2252-6.

6. Kharwade M., Subrahmanyam C.V.S., Sathesh P. R., 2013. Total and partial solubility parameters prediction: Lornoxicam in individual solvents, journal of pharmacy research.7,409-13.

7. Sharma S., Bhargav A., 2013. Preparation and Characterization of Lornoxicam Cyclodextrin Inclusion Complex for Solubility Enhancement \& Taste Masking, international journal of drug discovery and herbal research.3,325-34.

8. Zhang J., Xin T., Gao J., Fan W., Gao Y. and Qian S., 2013. Characterization of two polymorphs of lornoxicam, Journal of Pharmacy and Pharmacology. 65, 44-52.

9. Saricaoglu F., Dal D., Atilla P., Iskit A., Tarhan O, Asan E., Aypar U., 2008. Effect of intraarticular injection of lornoxicam on the articular cartilage \& synovium in rat, Indian J Med Res. 127,362-365.

10. Raziya S. K, Jyothir K., Hazarath.S. K., Karimunnisa.S. K., Suresh N., Gopinath C., 2012. Formulation and evaluation of lornoxicam microspheres by using ionic gelation technique, International Journal of Nature Sciences. 1,13-7.

11. Kumar P., Kulkarni G.T., 2013. Characterization of mucilage from artocarpus heterophyllus as pharmaceutical excipient, Journal of chronotherapy drug delivery. 4,31-43.

12. Narkhede S. B., Vidyasagar G., Jadhav A. G., Bendale A. R., Patel K. N., 2010. Isolation and evaluation of mucilage of Artocarpus heterophyllus as a tablet binder, Journal of Chemical and Pharmaceutical Research. 2, 161-6.

13. Sabale V., Patel V., Paranjape A., 2012. Isolation and characterization of jackfruit mucilage and its comparative evaluation as a mucoadhesive and controlled release component in buccal tablets, International journal of pharmaceutical investigation. 2, 61-9.

14. Lehr C. M., Bowstra J. A., Tukker J. J., Junginger H. E., 1990, Intestinal transit of bioadhesive microspheres in an in situ loop in the rat- A comparative study with copolymers and blends based on poly (acrylic acid), $\mathrm{J}$ Controlled Release. 13,51-62.

15. Parveen A., Syed I. A., 2014. Formulation and Evaluation of Mucoadhesive Microspheres of Lamivudine, 
International Journal of Pharmaceutical Sciences and Drug Research. 6,102-8.

16. Tuan H. T., Poudel B. K.,Marasini N.,Chi SC., Choi H.

G., 2013. Preparation and evaluation of raloxifen-loaded solid dispersion nanoparticles by spray-drying technique without an organic solvent, International journal of pharmaceutics. 443,50-7.

17. Bhandari S., Khisti N., 2012. Extraction less highperformance liquid chromatographic method for determination of Lornoxicam in human plasma, Asian journal of pharmaceutical and clinical research. 5,122-4. 